\title{
Hemophilia B (Christmas Disease) Variants and Carrier Detection Analyzed by DNA Probes
}

\author{
Man-Chiu Poon, David H. K. Chui, Margaret Patterson, Deborah M. Starozik, Leo S. Dimnik, and David I. Hoar \\ Departments of Medicine, Pediatrics, and Medical Biochemistry, University of Calgary and Foothills Hospital; Calgary Hemophilia \\ Clinic, and Molecular Diagnostic Laboratory, Alberta Children's Hospital; and The Canadian Red Cross Blood Transfusion Service, \\ Calgary, Alberta, Canada; and Department of Pathology, McMaster University, Hamilton, Ontario, Canada
}

\begin{abstract}
We have used two strategies to study 14 hemophilia B families from 11 kindreds for possible carrier detection and prenatal diagnosis. First, we sequentially used the Factor IX probes (sequentially with restriction enzymes Taq I, Xmn I, and Dde I), and the linked probes p45h (Taq I), p45d (Pst I), and 52a (Taq I) for restriction fragment length polymorphism (RFLP) analysis. Second, we searched for useful variant Taq I digestion fragments using the Factor IX complementary DNA. Two separate new Taq I variants in exon VIII were identified. Using both strategies, 11 of 14 families (from 9 of 11 kindreds) were informative for further studies. In five kindreds studied in detail, the carrier status of all 11 at risk females was determined and prenatal diagnosis could be offered to the offsprings of each of the six carriers identified. Thus, in this study, we have identified a higher proportion of informative families than has previously been reported.
\end{abstract}

\section{Introduction}

Hemophilia B (Christmas disease) is an X-linked hereditary bleeding disorder with functional deficiency of Factor IX, which affects $\sim$ 1:25,000 males (1). Female relatives of patients with hemophilia B often wish to know if they are carriers of this disorder, but only obligate carriers can be identified by pedigree analysis. Carrier detection by assaying for coagulant Factor IX activity (IX:C) ${ }^{1}$ alone, or in combination with Factor IX-related antigen (IX:Ag), lacks accuracy (1). Recently, the gene coding for Factor IX has been cloned and characterized (2-4), with the nucleotide sequence of the entire gene elucidated $(5,6)$. The complementary DNA (cDNA) and genomic probes have been successfully applied to track the affected $\mathrm{X}$ chromosome by re-

Portions of this work were presented at the 1986 meeting of The American Society for Clinical Investigation, Washington, D. C., and were published in abstract form (1986. Clin. Res. 34:662A).

Address correspondence and reprint requests to Dr. Poon, U. of Calgary Foothills Hospital, 1403-29th St. N. W., Calgary, Alberta, Canada T2N 2 T9.

Received for publication 21 July 1986 and in revised form 17 November 1986.

1. Abbreviations used in this paper: IX:Ag, Factor IX-related antigen; IX:C, coagulant Factor IX activity; RFLP, restriction fragment length polymorphism.

J. Clin. Invest.

(C) The American Society for Clinical Investigation, Inc. $0021-9738 / 87 / 04 / 1204 / 06 \$ 1.00$

Volume 79, April 1987, 1204-1209 striction fragment length polymorphism (RFLP) studies for the accurate detection of carriers (7-14). Initial studies with the restriction enzyme Taq I suggested that only $\sim 45 \%$ of the families had informative RFLP patterns (7). More recently, Xmn I (9), Dde I/Hinf I (9), Bam HI $(12,13)$, and Msp I (14) Factor IX intragenic RFLPs have been characterized, and it was estimated that about two-thirds of the families will be informative when Taq I, Xmn I and Dde I/Hinf I were used (9).

We have studied 11 hemophilia B kindreds for the detection of female carriers, and determined their suitability for future prenatal diagnosis using the same markers. In addition to using Factor IX cDNA and genomic probes to look for known RFLPs, we also used the cDNA probe to specifically look for Taq I variants as markers for the affected $\mathrm{X}$ chromosome. For the families that are not informative with these Factor IX probes, we have performed additional studies with probes to DNA segments closely linked to the Factor IX gene (52a, p45h, and p45d) in an attempt to increase the proportion of informative families.

\section{Methods}

Subjects. Members from 11 hemophilia B kindreds were studied. Nine of these kindreds are Caucasian, and two are Oriental. In nine of the kindreds, more than one affected male (with hemophilia B) are present. This is consistent with the mothers of the probands being obligate carriers of the defective Factor IX gene. The probands in the remaining two kindreds (kindreds B and D, Table I) are the only known affected males within these kindreds. All the patients studied had severe disease with IX:C $<0.01 \mathrm{U} / \mathrm{ml}$ as measured by the modified one-stage partial thromboplastin time assay (15), and none had developed inhibitors.

Gene probes. The Factor IX probes used include cDNA $(2,3)$ and genomic probe VIII, which spans exon IV (7). In some experiments, the $5^{\prime}$ and $3^{\prime}$ end of the Factor IX cDNA probe were derived by double digestion with Pst I (to excise insert) and Ava I (to generate 5' 674-base pair and 3' 763-base pair probes). These were identified respectively as $5^{\prime}-\mathrm{cDNA}$ and 3 '-cDNA probes. Probes to regions linked to the Factor IX gene used include 52a (16), as well as $p 45 \mathrm{~h}$ and p45d, which are two subclones of pX45D (17). All probe inserts were freed of vector by restriction digestion and electroelution before labeling using $\left[{ }^{32} \mathrm{P}\right] \mathrm{dCTP}$ and random primers (18).

Restriction enzyme analysis. Genomic DNA was isolated from the leukocytes in 7-10 $\mathrm{ml}$ of fresh or frozen-thawed EDTA-anticoagulated peripheral blood according to previously described methods $(19,20)$. 5$10 \mu \mathrm{g}$ of DNA was digested with one of the various restriction enzymes (Taq I, Xmn I, Dde I, and Pst I) under conditions specified by the commercial suppliers. Agarose gel electrophoresis, transfer of DNA fragments to nitrocellulose membranes, hybridization of DNA fragments with ${ }^{32} \mathrm{P}$ labeled probes and radioautography were carried out using established methods $(19,21)$. In some experiments, repeated hybridizations using different probes were carried out on nitrocellulose membranes containing Taq I digested DNA fragments. The Taq I RFLPs of $\mathrm{p} 45 \mathrm{~h}$ and 52a were assayed by simultaneously probing with equal amounts of the two inserts.

Identification of specific restriction enzyme sites. The Taq I restriction enzyme site changes responsible for variant Taq I fragments seen in 
kindreds A and B (see Results) were identified using the Factor IX sequence published by Yoshitake et al. (5) obtained through the Bionet data linked to the National Institutes of Health gene bank and a computer program (22).

\section{Results}

\section{RFLP analysis}

12 of the 13 patient-mother pairs and one patient-daughter pair in the 11 kindreds were studied sequentially using the appropriate Factor IX probes (sequentially with Taq I, Xmn I, and Dde I), p45h and 52a (Taq I), and p45d (Pst I), until heterozygosity of the polymorphic fragments of the females could be obtained (Table I). Kindred B was studied only with the Factor IX probes. Five mothers (families A1, C, D, E and F) were heterozygous using the genomic Factor IX probe/Taq I enzyme combination alone. Sequential studies on the remaining showed two additional informative mothers (familes A2 and A3) with the genomic Factor IX probe/Xmn I combination; one additional (family G) with the $\mathrm{p} 45 \mathrm{~h}$ probe/Taq I combination; and two additional (families $\mathrm{H}$ and $\mathrm{I}$ ) with the $52 \mathrm{a}$ probe/Taq I combination. Thus, a total of 10 out of 14 females were informative. Family studies were carried out for seven of the patient-mother pairs in five kindreds (Table I).

Kindred $A$. Families A1, A2, and A 3 are from a large kindred, with the mothers being daughters of a man with Christmas disease. Mother Al was informative with the genomic IX probe/ Taq I combination, and her daughter was identified as carrier who was heterozygous for the polymorphic fragments suitable for future prenatal diagnosis. Mother A2 was informative for the genomic IX probe/Xmn I combination, and her daughter was identified as a noncarrier. Mother A3 was informative for the genomic IX probe/Xmn I combination, and both of her daughters were identified as carriers but were homozygous for the polymorphic fragments. Sequential probe/enzyme analysis show both daughters were informative with the $\mathrm{p} 45 \mathrm{~h}$ probe/Taq I combination for future prenatal diagnosis. The mother in family A3 was also informative with the 52a probe/Taq I combination and family studies confirmed the carrier status of the two daughters (Table I).

Kindred $B$. The genomic IX probe/Taq I RFLPs could be used to exclude carrier status in the maternal aunt. However, neither Taq I nor Xmn I RFLPs were informative in the mother.

Kindred $C$. Genomic IX probe/Taq I analysis indicates that the daughter is a carrier, but this would not be informative for future prenatal diagnosis. Sequential studies established that the cDNA probe/Dde I combination could be used for this purpose. The results on two independent sets of specimens are identical, and nonpaternity is evident in this family.

Kindred $D$. The genomic IX probe/Taq I analysis shows that neither of the daughters carries the $\mathrm{X}$ chromosome of the proband, which indicates that they are not carriers.

Kindred $E$. Genomic IX probe/Taq I analysis shows that the daughter is not a carrier.

\section{Detection of unusual Taq I variants}

Variant Taq I fragments were found in patients of kindreds A and $B$. All these patients had severe disease (IX:C $<0.01 \mathrm{U} / \mathrm{ml}$ ) with the IX:Ag $<0.06 \mathrm{U} / \mathrm{ml}$ by the Laurell immunoelectrophoresis assay (23).

Kindred $A$. Each of the three patients had a 1.3-kilobase (kb) fragment with the genomic probe/Taq I RFLP (Table I, Fig. 1 a). Independent Taq I digestion as well as repeat hybridization studies with the total cDNA probe revealed that all three patients had both 1.3- and 1.8-kb fragments with loss of the constant 1.5-kb fragment (Fig. $1 b$ and Table I). In contrast, the $3^{\prime}$ cDNA probe disclosed a $1.8-\mathrm{kb}$ fragment in each of these patients instead of the 1.5-kb fragment normally found (data not shown). These results indicate that the $1.8-\mathrm{kb}$ fragment is a new variant due to the loss of a Taq I site that would normally result in the constant 1.5-kb Taq I fragment, and that the changed Taq I site is $3^{\prime}$ to the Ava I cDNA digestion site (Fig. 2). Hybridization of Xmn I DNA digest by the $3^{\prime}$ and $5^{\prime}$ cDNA probes showed normal fragment patterns (identical to the patterns in Fig. 3, $b$ and $d$ ), excluding the possibility of a gross gene deletion to account for the Taq I variant pattern. Based on the sequence published by Yoshitake et al. (5), and a computer search, the Taq I digestion site (TCGA) change could be traced to exon VIII at nucleotides 30873 to 30876 . Studies using both the genomic and cDNA probes confirmed that the variant $1.8-\mathrm{kb}$ fragment was present in each obligate carrier and in each of the two carriers identified by RFLP analysis (Fig. 1, $a$ and $b$, and Table I).

Kindred $B$. Total cDNA analysis of Taq I digests from the only known Christmas disease patient in this family disclosed a variant $3.0-\mathrm{kb}$ fragment with loss of the constant $2.7-\mathrm{kb}$ fragment. These changes in fragment size could be discerned using the $3^{\prime}$ cDNA probe (Fig. $3 \mathrm{c}$ ), while the $2.7-\mathrm{kb}$ and the $3.0-\mathrm{kb}$ fragments were absent when the 5'-cDNA probe was used (Fig. $3 a$ ). In addition, the Xmn I fragments were unchanged (Fig. 3, $b$ and $d$ ). These studies suggest that the $3.0-\mathrm{kb}$ fragment is a result of a loss of a Taq I site that would normally result in a $2.7-\mathrm{kb}$ fragment after Taq I digestion (Fig. 2). Based on the nucleotide sequence published by Yoshitake et al. (5) and on a computer search, the Taq I digestion site (TCGA) change could be traced to exon VIII, at nucleotides 31131 to 31134 . The same variant 3.0-kb fragment could be identified in the mother and maternal grandmother, who are therefore carriers, but not in the maternal aunt (whose carrier status was also excluded by RFLP analysis) (Fig. $3 c$ and Table I).

\section{Discussion}

We have studied 11 hemophilia B kindreds with DNA probes for carrier detection and for assessment of prenatal diagnosis possibilities amongst the carriers. Our approach was to sequentially study the female relatives with Factor IX probes (cDNA and genomic probe VIII), and linked probes (p45h, 52a, and p45d) for the known RFLPs and to identify Factor IX variants. Of the 13 mothers and 1 daughter of probands from these 11 kindreds, 11 mothers (79\%) from 9 kindreds (Table I) were informative (heterozygous for the RFLPs, or possession of variant fragments found in the patients). This proportion is higher than the $40-66 \%$ using Factor IX RFLP analysis alone (7-12). We determined the carrier status of all 11 at risk females in 5 kindreds, and also determined that prenatal diagnosis could be offered to the offsprings of each of the 6 carriers identified.

Using the Factor IX probes, RFLP studies with Taq I and Xmn I identified 7 females informative out of $14(50 \%)$ in the 11 kindreds. This proportion is similar to that reported by others (9). The additional Dde I RFLP should provide a further $16 \%$ informative females (9), but was not useful in our small series. We did not attempt further with Bam HI and Msp I with the Factor IX probes. Bam HI has been found to be useful more 
Table I. RFLP or Variant Fragment Phenotypes Determined with Various DNA Probe-Restriction Enzyme Combinations

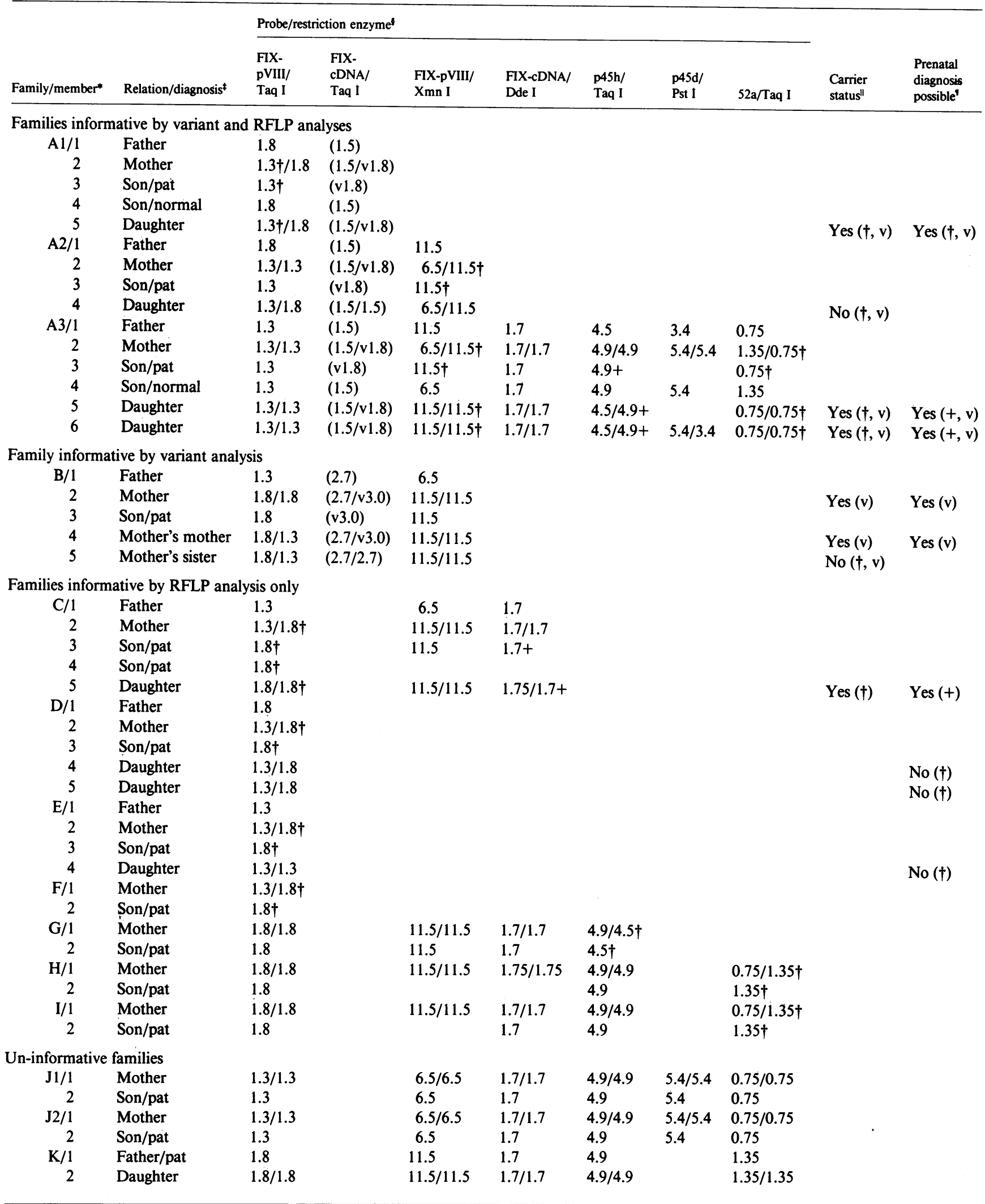

The phenotypes are designated by the fragment size in kilobases. * Families A1, A2, and A3 are from the same kindred A; J1 and J2 are from the same kindred J. ${ }^{\ddagger}$ Pat, hemophilia B patient. ${ }^{8}$ FIX-pVIII, Factor IX genomic probe VIII; FIX-cDNA: Factor IX total cDNA probe. Under FIX-cDNA/Taq I, only variant ( $v$ ) fragment data on families A and B are recorded: in family A, the normal fragment is $1.5 \mathrm{~kb}$, and the variant fragment is $1.8 \mathrm{~kb}(\mathrm{vl} .8)$; in family $\mathrm{B}$, the normal fragment is $2.7 \mathrm{~kb}$, and the variant fragment is $3.0 \mathrm{~kb}(\mathrm{v} 3.0)$. In all RFLP analyses, the fragments associated with the hemophilia B carrying chromosomes are denoted by $\dagger$ or + . "The carrier status of an at risk female is determined by the presence or absence of a DNA fragment associated with the disease carrying chromosome denoted by $\dagger$ or $\mathbf{v}$. 'Prenatal diagnosis for a female carrier is made possible by the ability to identify the disease carrying $\mathrm{X}$ chromosome denoted by $\dagger,+$, or $\mathrm{v}$. 

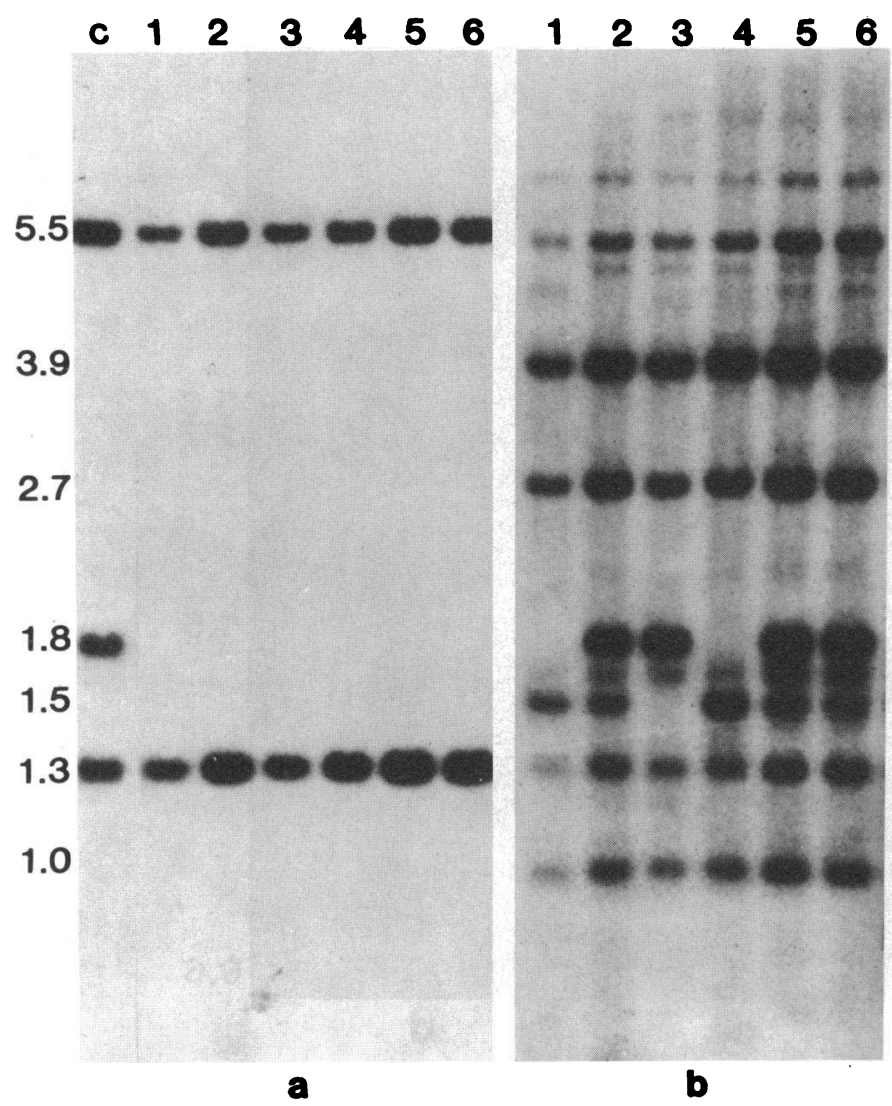

Figure 1. Taq I DNA digests of family A3 members probed sequentially with Factor IX genomic probe VIII (panel a), linked probes p45h and 52a combined (panel $c$ ) and Factor IX cDNA (panel b). Fragment sizes are given in kilobases on left and right margins; $p 45 \mathrm{~h}$ and 52a fragments are identified by brackets with constant fragments followed by the letter $c$. The numbers across the top correspond to those of the family A3 in Table I, and lane $c$ is a 1.8/1.3-kb unrelated

for the blacks (12), and the Msp I site is located at a short distance from the Taq I site, such that the two RFLPs might be expected to show significant linkage disequilibrium (14), limiting its usefulness.

RFLP studies with the linked probes has provided informative results for three additional mothers, one with $\mathrm{p} 45 \mathrm{~h}$ and two with 52a (Table I). Both of these linked probes have Taq I RFLPs and could be easily studied by simultaneous hybridization of the filters containing Taq I digested DNA fragments originally used for Factor IX probes (Fig. 1). A potential problem with this approach is the possible recombination between the Factor IX gene and the linked DNA fragments (24). To our knowledge, recombination has not yet been reported between the Factor IX and $\mathrm{p} 45 \mathrm{~h}$ or $\mathrm{p} 45 \mathrm{~d}$ probes; however, recombination frequency of 1:55 has been reported for the Factor IX and 52a genes (16).

It is of note that nonpaternity was documented in one family (kindred C). This finding has not affected the carrier state determination on the daughter or altered the ability to provide her with prenatal diagnosis in the future (Table I). If unrecognized, nonpaternity could negate the predictive value of this type of study.

We have also identified variant Taq I fragments in 2 of 11 kindreds using the total cDNA probe. In kindred $\mathrm{A}, \mathrm{a} 1.8-\mathrm{kb}$ fragment was identified in place of the $1.5-\mathrm{kb}$ fragment, and the

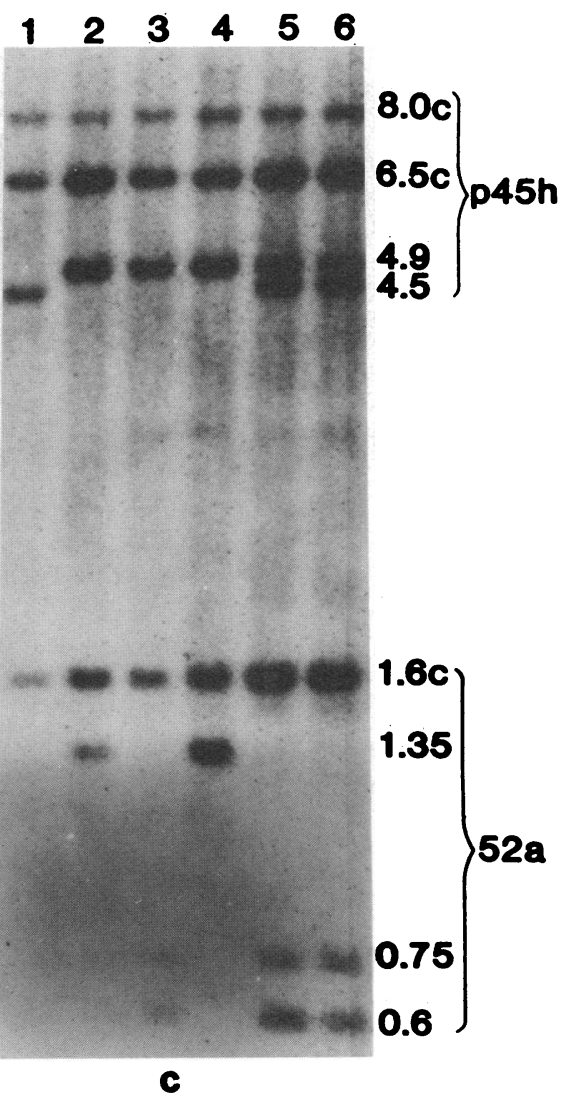

heterozygous female. The faint bands in panel $b$ correspond to those seen in panel $\mathrm{c}$ as the previous hybrid signal had not decayed completely. In panel c, the 0.75 - and $0.6-\mathrm{kb}$ bands of lanes $1-3$ are only faintly visible and did not reproduce well. These individuals have only one X chromosome with the 0.75/0.6-kb RFLP (single dose), compared with the two females in lanes 5 and 6 who have two X chromosomes with the 0.75/0.6-kb RFLP (double dose).

changed sequence could be traced to nucleotide sequence 30873 to 30876 , affecting amino acids 251 or 252 (Ile or Arg). In kindred B, a $3.0-\mathrm{kb}$ fragment was present in place of the $2.7-\mathrm{kb}$ fragment, and the changed sequence could be traced to nucleotide sequence 31131 to 31134 , affecting amino acids 337 or 338 (Leu or Arg).

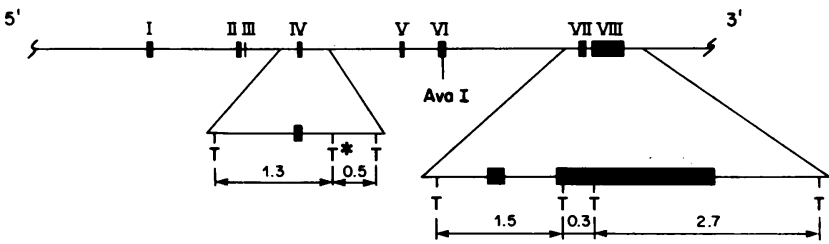

Figure 2. Factor IX genomic map showing the Taq I digestion sites (T) around exon IV, as well as exons VII and VIII. The Taq I fragments around exon IV represent those recognized by genomic Factor IX probe VIII, with the $T^{*}$ representing the polymorphic Taq I site. The variant Taq $I$ fragments in families $A$ and $B$ recognized by Factor IX cDNA probe are the result of Taq I site changes in exon VIII. A loss of the $5^{\prime}$ Taq I site in exon VIII changes the fragment size from 1.5 to $1.8 \mathrm{~kb}$ (kindred A), while a loss of the $3^{\prime}$ Taq I site in exon VIII changes the fragment size from 2.7 to $3.0 \mathrm{~kb}$ (kindred B). The Ava I site that separates the $3^{\prime}$ and $5^{\prime}$ cDNA probe (see Methods) is also shown. 


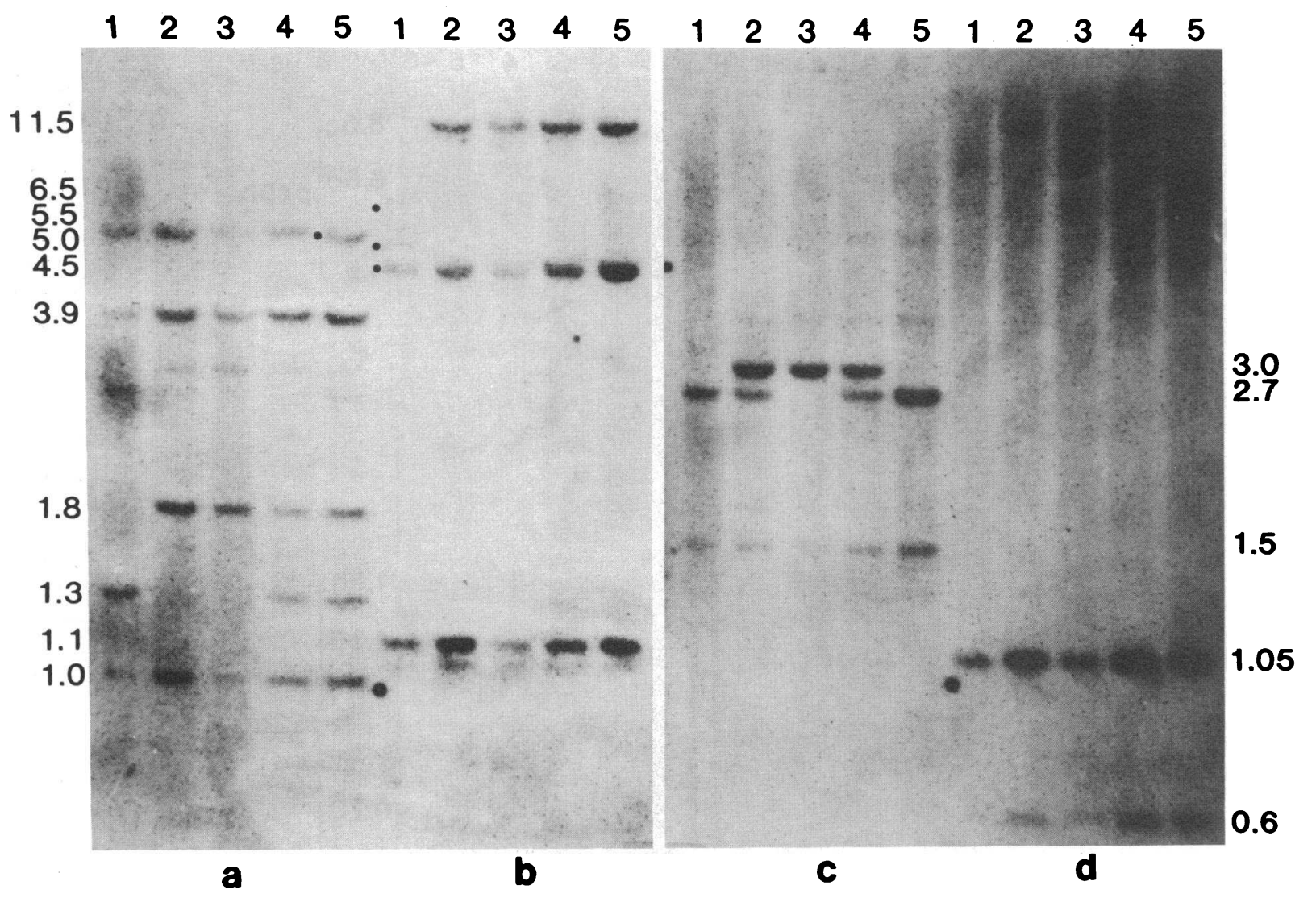

Figure 3. Southern blot analysis of family B with Taq I and Xmn I using $5^{\prime}$ cDNA ( $a$ and $b$ ) and $3^{\prime}$ cDNA ( $c$ and $d$ ) Factor IX cDNA probes (see Methods and Fig. 2). Fragment sizes are given on the margins in kilobases (dots to the left of the bands on $a$ and $b$ identify the

The changed nucleotide sequence in each case occurs in exon VIII, which encodes a portion of the catalytic domain of the Factor IX molecule (5). This region has not previously been recognized as having polymorphic sites, suggesting that the changes may represent a missense or nonsense mutation responsible for the Christmas disease phenotype. Taq I and Msp I sites that contain the $\mathrm{CpG}$ dinucleotide appear to show a higher frequency of mutation in human DNA (25), and Taq I site changes have been observed as the basis for classic hemophilia (26). However, the possibility that these changes represent extremely rare normal variant sequence cannot be completely excluded. Normal variant changes affecting the activation peptide coding region of the Factor IX gene have recently been described (27).

The change in Taq I fragment size in each case without loss of other constant fragments and the absence of changes with Xmn I (Fig. 3, and data not shown) suggest that a deletion (unless very small) is unlikely. None of the patients affected produce inhibitor, a frequent association with Factor IX defects produced by gross gene deletions (28-30). The precise nature of the Taq I site change in each case will require nucleotide sequencing, which is now under way in our laboratories.

These variant Taq $I$ fragments are useful in tracking the affected X chromosome. They have been used here to successfully determine the carrier status of the female relatives and for future prenatal diagnoses. In family $\mathrm{A} 3$, the variant fragment would be superior to the linked probe 52a for this purpose, as possible recombination is a concern whenever linked probes are used.

cluster of fragments from 6.5 to $4.5 \mathrm{~kb}$ ) and the numbers across the top correspond to the members of family B in Table I. The filters were first probed with the $3^{\prime} \mathrm{cDNA}$ ( $c$ and $d$ ), and after 1 wk reprobed with the $5^{\prime}$ cDNA $(a$ and $b$ ).

Our studies illustrate the importance of using both total cDNA and genomic probes for study of Christmas disease families. The identification of variant fragments would not have been possible with the genomic probe alone. In another study, the cDNA probe was useful for the identification of a Factor IX intragenic deletion (31). On the other hand, the fragment pattern from the cDNA probe/Taq $I$ in kindred $A$ would have been extremely difficult to interpret without the RFLP patterns from the genomic probe, as the variant $1.8-\mathrm{kb}$ fragment is identical in size to one of the Taq I RFLPs.

Two of the kindreds (B and D) had no family history of hemophilia and a new mutation affecting only the proband could not be excluded. It is of interest that in family $B$, the variant fragment observed in the affected child is also present in the previous two generations. Kindred $D$ could only be studied by RFLP approach. In this instance, the result is valid only when the female relatives are identified not as carriers, as is the case with the daughters of this family. The noncarrier status of the maternal aunt of kindred B could also be predicted by RFLP studies.

Many female relatives of hemophilia patients desire to know if they are carriers, and genetic counseling has become an integral part of the comprehensive hemophilia management. Some female carriers often wish to learn more about the upbringing of a hemophilic child, and the coping with emotions and schooling (32). Other female carriers may choose prenatal diagnosis for management options or for the preparation for care at delivery and during the early postnatal period. The diagnostic approach reported here allows identification of carrier status in at risk 
females in up to $80 \%$ of families, and can provide reliable results necessary for prenatal diagnosis by DNA analysis of chorionic villi obtained during the first trimester of pregnancy (33).

\section{Acknowledgments}

We thank Dr. G. G. Brownlee (University of Oxford, Oxford, United Kingdom) for providing the Factor IX cDNA probe and the genomic probe VIII used at McMaster University, Dr. E. Davie (University of Washington, Seattle, WA) for the Factor IX cDNA probe used at the University of Calgary, Dr. D. Drayna (University of Utah, Salt Lake City, UT) for the probe 52a, and Dr. B. N. White (Queen's University, Kingston, Ontario, Canada) for probes p45h and p45d. We also thank Cathy Bennett for obtaining many of the blood samples, and Karen Reeves for preparation of the manuscript.

This work was supported in part by research funds from the Alberta Medical Service Inc. Foundation (grant 438), Canadian Red Cross Blood Transfusion Service (grant CA83-01), Alberta Heritage Foundation for Medical Research, the Alberta Hereditary Diseases Program, and the Medical Research Council of Canada (grant MT-5004 to Dr. Chui). Dr. Hoar is a Scholar of the Alberta Heritage Foundation for Medical Research.

\section{References}

1. Thompson, A. R. 1986. Structure, function, and molecular defects of factor IX. Blood. 67:565-572.

2. Kurachi, K., and E. W. Davie. 1982. Isolation and characterization of a cDNA coding for human factor IX. Proc. Natl. Acad. Sci. USA. 79: 6461-6464.

3. Choo, K. H., K. G. Gould, D. J. G. Rees, and G. G. Brownlee. 1982. Molecular cloning of the gene for human anti-haemophilia factor IX. Nature (Lond.). 299:178-180.

4. Jaye, M., H. de la Salle, F. Schamber, A. Balland, V. Kohli, A. Findeli, P. Tolstoshev, and J.-P. Lecocq. 1983. Isolation of a human anti-haemophilia factor IX cDNA clone using a unique 52-base synthetic oligonucleotide probe deduced from the amino acid sequence of bovine factor IX. Nucleic Acids Res. 11:2325-2335.

5. Yoshitake, S., B. G. Schach, D. C. Foster, E. W. Davie, and K. Kurachi. 1985. Nucleotide sequence of the gene for human factor IX (antihemophilia factor B). Biochemistry. 24:3736-3750.

6. Anson, D. S., K. H. Choo, D. J. G. Rees, F. Giannelli, K. Gould, J. A. Huddleston, and G. G. Brownlee. 1984. The gene structure of human anti-haemophilic factor IX. EMBO (Eur. Mol. Biol. Organ.) J. 3:1053-1060.

7. Giannelli, F., D. S. Anson, K. H. Choo, D. J. G. Rees, P. R. Winship, N. Ferrari, C. R. Rizza, and G. G. Brownlee. 1984. Characterization and use of an intragenic polymorphic marker for detection of carriers of haemophilia B (factor IX deficiency). Lancet. i:239-241.

8. Grunebaum, L., J.-P. Cazenave, G. Camerino, C. Kloepfer, and J.-L. Mandel. 1984. Carrier detection of hemophilia B by using a restriction site polymorphism associated with the coagulation factor IX gene. J. Clin. Invest. 73:1491-1495.

9. Winship, P. R., D. S. Anson, C. R. Rizza, and G. G. Brownlee. 1984. Carrier detection in haemophilia B using two further intragenic restriction fragment length polymorphisms. Nucleic Acids Res. 12:88618872.

10. Hassan, H. J., M. Orlando, A. Leonardi, C. Chelucci, R. Guerriero, P. M. Mannucci, G. Mariani, and C. Peschle. 1985. Intragenic factor IX restriction site polymorphism in hemophilia B variants. Blood. 65: 441-443.

11. Connor, J. M., A. F. Pettigrew, I. M. Hann, C. D. Forbes, G. D. O. Lowe, and N. A. Affara. 1985. Application of an intragenic genomic probe to genetic counselling for haemophilia B in the west of Scotland. J. Med. Genet. 22:441-446.

12. Driscoll, M. C., C. H. Miller, M. W. Hilgartner, and L. M. Aledort. 1985. Gene analysis and DNA polymorphisms in hemophilia B. Blood. 66(Suppl. 1):333a. (Abstr.)
13. Hay, C. W., K. A. Robertson, S.-L. Yong, A. R. Thompson, G. H. Growe, and R. T. A. MacGillivray. 1986. Use of a BamHI polymorphism in the factor IX gene for the determination of hemophilia B carrier status. Blood. 67:1508-1511.

14. Camerino, G., I. Oberle, D. Drayna, and J. L. Mandel. 1985. A new MspI restriction fragment length polymorphism in the hemophilia B locus. Hum. Genet. 71:79-81.

15. Crum, E. D., J. R. Shainoff, R. C. Graham, and O. D. Ratnoff. 1974. Fibrinogen Cleveland II. An abnormal fibrinogen with defective release of fibrinopeptide A. J. Clin. Invest. 53:1308-1319.

16. Drayna, D., and R. White. 1985. The genetic linkage map of the human X chromosome. Science (Wash. DC). 230:753-758.

17. Mulligan, L. M., M. A. Phillips, C. J. Forster-Gibson, J. Beckett, M. W. Partington, N. E. Simpson, J. J. A. Holden, and B. N. White. 1985. Genetic mapping of DNA segments relative to the locus for the fragile-X syndrome at Xq27.3. Am. J. Hum. Genet. 37:463-472.

18. Feinberg, A. P., and B. Vogelstein. 1983. A technique for radiolabelling DNA restriction endonuclease fragments to high specific activity. Anal. Biochem. 132:266-267.

19. Hoar, D. I., D. B. Haslam, and D. M. Starozik. 1984. Improved direct molecular diagnosis and rapid fetal sexing. Prenatal. Diagn. 4: 241-247.

20. Kan, Y. W., and A. M. Dozy. 1978. Polymorphism of DNA sequence adjacent to human $\beta$-globin structural gene: relationship to sickle mutation. Proc. Natl. Acad. Sci. USA. 75:5631-5635.

21. Southern, E. M. 1975. Detection of specific sequences among DNA fragments separated by gel electrophoresis. J. Mol. Biol. 90:503517.

22. Lagrimini, L. M., S. T. Brentano, and J. E. Donelson. 1984. A DNA sequence analysis package for the IBM personal computer. Nucleic Acids Res. 12:606-614.

23. Laurell, C.-B. 1966. Quantitative estimation of protein by electrophoresis in agarose gel containing antibodies. Anal. Biochem. 15:4552.

24. Graham, J. B., P. P. Green, R. A. McGraw, and L. M. Davis. 1985. Application of molecular genetics to prenatal diagnosis and carrier detection in the hemophilias: some limitations. Blood. 66:759-764.

25. Barker, D., M. Schafer, and R. White. 1984. Restriction sites containing CpG show a higher frequency of polymorphism in human DNA. Cell. 36:131-138.

26. Gitschier, J., W. I. Wood, E. G. D. Tuddenham, M. A. Shuman, T. M. Goralka, E. Y. Chen, and R. M. Lawn. 1985. Detection and sequence of mutations in the factor VIII gene of haemophiliacs. Nature (Lond.). 315:427-430.

27. McGraw, R. A., L. M. Davis, C. M. Noyes, R. L. Lundblad, H. R. Roberts, J. B. Graham, and D. W. Stafford. 1985. Evidence for a prevalent dimorphism in the activation peptide of human coagulation factor IX. Proc. Natl. Acad. Sci. USA. 82:2847-2851.

28. Peake, I. R., B. L. Furlong, and A. L. Bloom. 1984. Carrier detection by direct gene analysis in a family with haemophilia B (factor IX deficiency). Lancet. i:242-243.

29. Giannelli, F., K. H. Choo, D. J. G. Rees, Y. Boyd, C. R. Rizza, and G. G. Brownlee. 1983. Gene deletions in patients with haemophilia $B$ and anti-factor IX antibodies. Nature (Lond.). 303:181-182.

30. Bernardi, F., J. Del Senno, R. Barbieri, D. Buzzoni, R. Gambari, G. Marchetti, F. Conconi, F. Panicucci, M. Positano, and S. Pitruzzello. 1985. Gene deletion in an Italian haemophilia B subject. J. Med. Genet. 22:305-307.

31. Chen, S.-H., S. Yoshitake, P. F. Chance, G. L. Bray, A. R. Thompson, C. R. Scott, and K. Kurachi. 1985. An intragenic deletion of the Factor IX gene in a family with hemophilia B. J. Clin. Invest. 76: 2161-2164.

32. Markova, I., C. D. Forbes, and M. Inwood. 1984. The consumers' view of genetic counseling of hemophilia. Am. J. Med. Genet. 17:741752.

33. Tonnesen, T., F. Sondergaard, F. Guttler, I. Oberle, J. P. Moisan, J. L. Mandel, M. Hauge, and E. M. Damsgard. 1984. Exclusion of hemophilia B in male fetus by chorionic villus biopsy. Lancet. ii:932. 